\title{
SYSTEMIC RISK MANAGEMENT IN THE BANK ACTIVITY: NEW APPROCHES
}

\author{
Professor PhD, Marin Oprițescu, University of Craiova, finante.ucv@gmail.com \\ Teaching Assistant PhD Student, Alina Georgiana Manta, University of Craiova, \\ iacobescua@yahoo.com
}

ABSTRACT: The role of the bank system as essential link the saving-investment process makes of its stability a priority on the agenda of the public authorities. One of the major objectives of a central bank is to prevent the systemic risk by promoting an efficient bank monitoring, which should contribute to the achievement of the stability and viability of the entire financial system. Thus, the central banks developed methods and processes for the continual supervising and evaluation of the banks - premises of the prevention of the apparition of a great variety of bank crisis or other unpleasant surprises regarding the entities of the bank system.

Key words: model, systemic risk, warning in time system.

JEL codes: G21, G24, G32

\section{General considerations}

The bank activity involves risks which are manifested at the level of each bank entity, but which can be transmitted in the entire bank system or, in the case of the international/transnational banks, in more bank systems. The banks pursue the reaching of some objectives that are many times divergent, in that they use specific instruments both in order to raise its quota on the market, and also to attract available capitals necessary to the performance of some speculative transactions.

On the other hand, the changing environment the banks operate in, marked by the increase of the volatility, the internationalisation and the liberalization of the financial markets increased the effect of contagion, as it was proven by the propagation of the effects of the financial crisis at the end of the 90s in Thailand to the rest of Asia, eastern Europe and South America, on the entire world bank system. These events determined the supervising authorities to pay an increased attention to the financial risks and, implicitly, to the administration of the systemic risk.

\section{The models used in the global appreciation of the bank risks}

In order to prevent the systemic risk, in order to assure the stability and the viability of the entire bank system, the monetary authorities developed systems of monitoring the activity and the results of the banks. All the bank systems have at least an authority of regulation and supervising, which have responsibilities, powers of regulation and implementation of the different assumed decisions. In most of the bank systems, the regulation and supervising authority goes to the central bank. In order to be efficient, the supervising authorities must rejoice an appropriate implementation power and an adequate degree of autonomy, most of the times they having to resist the pressures exercised by the government, banks, stock holders, deponents or creditors.

The supervising authority normally uses a top down approach that is focused upon the evaluation of the manner the banks identify, quantify, administrate and control the risks, and as it is the 
case, establish a diagnostic for the observed problems. In the practice of the banking supervising, directed towards the evaluation of the risk and the identification of the potential problems that can affect the bank system, the authorities use instruments and procedures of global appreciation of the bank risks, known as warning in time systems. The most known supervising system of the bank rating is the CAMEL model, used in USA. Thus, Federal Reserve Bank evaluates the banks thanks to a category of performances included in the CAMEL system (acronym formed of the names of the composing elements of the process of examination of the safety and solidity of the banks - solvability, the quality of the assets, the management, the incomes and the liquidity). Each element is attributed grades from 1 to 5 . The banks that have received the grades 4 or 5 are considered banks in difficulty, their activity being considered risky and they are exposed to bankruptcy. These are strictly supervised and forced by the bank authorities to optimise their financial behaviour.

In the American approach of the risk position of a bank, the bank performance is defined by solidity, given by an appropriate adequacy of the capital. The management of the bank and the profitableness (which is the purpose of each bank) are not objectives of the Central Bank, being considered the most efficient means of minimization of the risks and covering of the exposure to the risk.

The analysis systems of the financial indicators based upon the prudential norms suppose the monitoring and the analysis of the main economical-financial indicators of a bank institution: the adequacy of the capital, the liquidity, the exposure to a single debtor etc. and in case they exceed the established limits, the supervising authority interferes aggressively.

The comprehensive methods of evaluation of the bank risks suppose an evaluation of the risk profile of the bank through the quantification of all the risks that correspond to every activity treated distinctively and the attribution of certain scores for every activity. The cores are afterwards aggregated so that the final score of the bank as a whole is obtained.

The statistic models have the advantage that they identify those risks that have the greatest possibility to generate situations adverse to the bank, based on the prevision of the probability of the future evolutions. These models remove all the disadvantages of using the static models in an economy characterized by dynamism. The most used models are the ones which estimate a probability of a decrease of the grade held by the bank, predict a supervising incapacity or estimates potential losses which can induce, under extreme conditions, banking bankruptcies. The misfit of these models stands in the fact that they suppose the existence of some considerable historic registers, so that the solutions prove to be veridical. At the same time, the solutions of the models depend on the right choice of the variables upon which the provision is made.

The bank rating and early warning system used by the National Bank of Romania is CAAMPL. This was implemented in 1999 in order to promote an efficient supervising, aligned to the international practices and standards. The fundamental objective of the supervising system is the identification initially of those banks that are considered inefficient, according to the evaluation criteria of the financial and operational aspects established by the monetary authority or manifest adverse trends, requiring a special supervising.

The components of analysis of the CAAMPL system are: the adequacy of the capital (C), the quality of the assets (A), the quality of the stock holding (A), the management (M), the profitableness $(\mathrm{P})$ and the liquidity (L). In determining the composed degree of classification, from the five elements, four are analysed in accordance to a series of indicators, each bank being attributed a composed rating and a final score, which reflects the total of points given to the indicators which define the CAAMPL components (the banks are classified into five categories, the superior level being represented by the rating 1). The final grade is obtained by summing the value of the rating for each indicator, to which is added the value of the rating for the components "the quality of the stock holding" and "the quality of the management".

From 2004 BNR has modified the modality of evaluation of the management of the banks by using some models of evaluation of the risks of the scorecard type which allow the calculation 
and the attribution of a grade for each component of the management system: the planning, the monitoring, the control, the evaluation. These data-processing applications have been possible as a consequence of accessing the PHARE financing funds and the consultancy offered within these projects. From 2005 BNR has modified the approach in the evaluation of the L component, so that it would quantify the capacity to plan, monitor and control the bank risks, to evaluate the adequacy of the internal audit systems.

The rating system used by BNR is submitted to a continuum process of perfecting, imposed by a multitude of factors, of which we mention: the evolution of the national economy, the evolution and the vulnerability of the bank system, the necessity of the harmonisation of the bank legislation to the international standards. For instance, upon the liquidity problems the Commercial Bank Unirea, Eurom Bank (ex Dacia Felix) or Bancorex dealt with during 1998-2000, the National Bank of Romania included two essential components (the quality of the stock holding and the management) and improved the liquidity component (2001) by determining the liquidity index as report between the effective liquidity and the necessary one.

In order to consolidate the supervising activity which allows BNR to plan, monitor, control the bank risks and also to evaluate the quality of the informational systems at the level of each bank, the banks rating system CAAMPL includes a new component the market risk sensitivity $(S)$. This one evaluates the market risk and the first simulation of this component was achieved on June $30^{\text {th }}$, 2004. According to the theoretic model, the banks were submitted to some interest rate shocks consisting in the modification of the interest rate by four percents for the national currency and tow percents for the unique European currency and the American dollar. The scenario was chosen so that it would generate a loss at the level of each bank. The conclusion of the simulation was that, despite the insufficient development of the derived financial instruments meant to reduce the market risk, most of the Romanian banks registered low exposures to the interest rate risk. The weakness of this simulation was the unavailability of some data necessary to the evaluation of the sensitivity for some banks. According to the model, the weight of the quantitative analysis was of $40 \%$, the difference being represented by an analysis of qualitative type.

According to CAAMPL, the totally active weights of the banks classified in accordance to the five types of rating, during 1999/2006, is presented in figure no. 1.
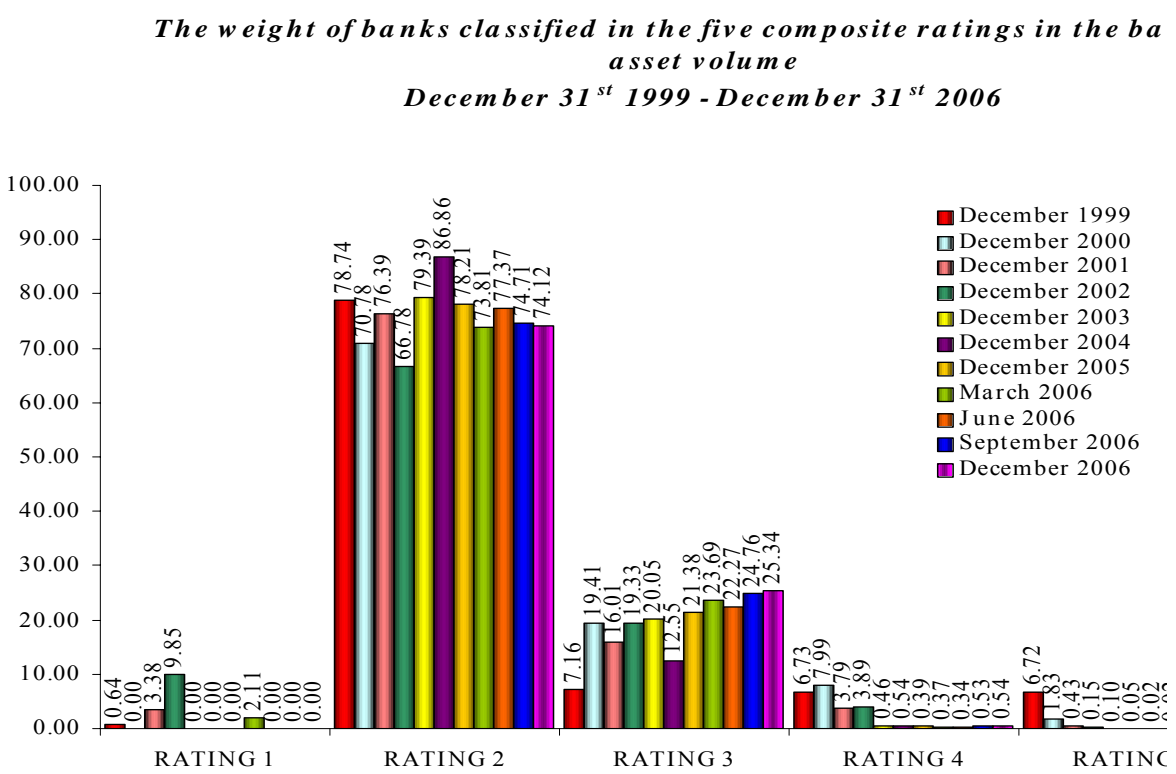

Fig. no.1. - The weight of banks classified in the five composite ratings in the banking asset volume during 1999-2006

Source: National Bank of Romania, Romanian Banking System, 2006, p.88

From the presented data we the following can be observed:

- the increase of the ratings granted to the banks starting with 1999, year that marls the 
beginning of the process of restructuration of the bank system;

- the polarization of the bank system on the superior floor of the bank rating system, containing the banks with 2 and 3 rating, which denotes the consolidation of the bank system.

However, in 2007, according to a study elaborated by BNR [Georgescu Florin, 2007] we observe that more banks were retrograded by BNR from rating group 2 to group 3 at the end of September 2005, mainly because of the deterioration of the profitability indicators.

According to the estimations presented by the prime-vice governor of BNR, Florin Georgescu, six banks received weaker evaluation grades as compared to December 2006, exiting rating group 2. Thus, the number of the banks included in this group decreased from 17 to 11 . In exchange the number of the banks of the rating group 3 increased from 19 to 26, and the one of the banks from the rating group 4, increased from 1 to 3 , given the fact that the total number of the credit institutions on the market increased from 37 to 40 . Presently, the rating group 2 represents the best efficiency points the banks in the system can obtain. From the end of 2003, no bank had been included in the rating group 1 .

It is also shown in the study that there is a slight degradation of the profitability rate of the banks, against the expenses for the expansion of the networks of units and the increase of the number of wage-earners, and also the reduction of the interest margins. Thus, BNR pursues the financial solidity of the banks on the market and the degree of potential contagion after a six component rating system - CAAMPL. BNR does not make public the ratings given to every bank, as the independent financial evaluation agencies do, however it presents from time to time the number of the banks which are included in every rating step. According to the data by the end of September 2007, no bank on the market had received the alarm points, which correspond to rating group 5.

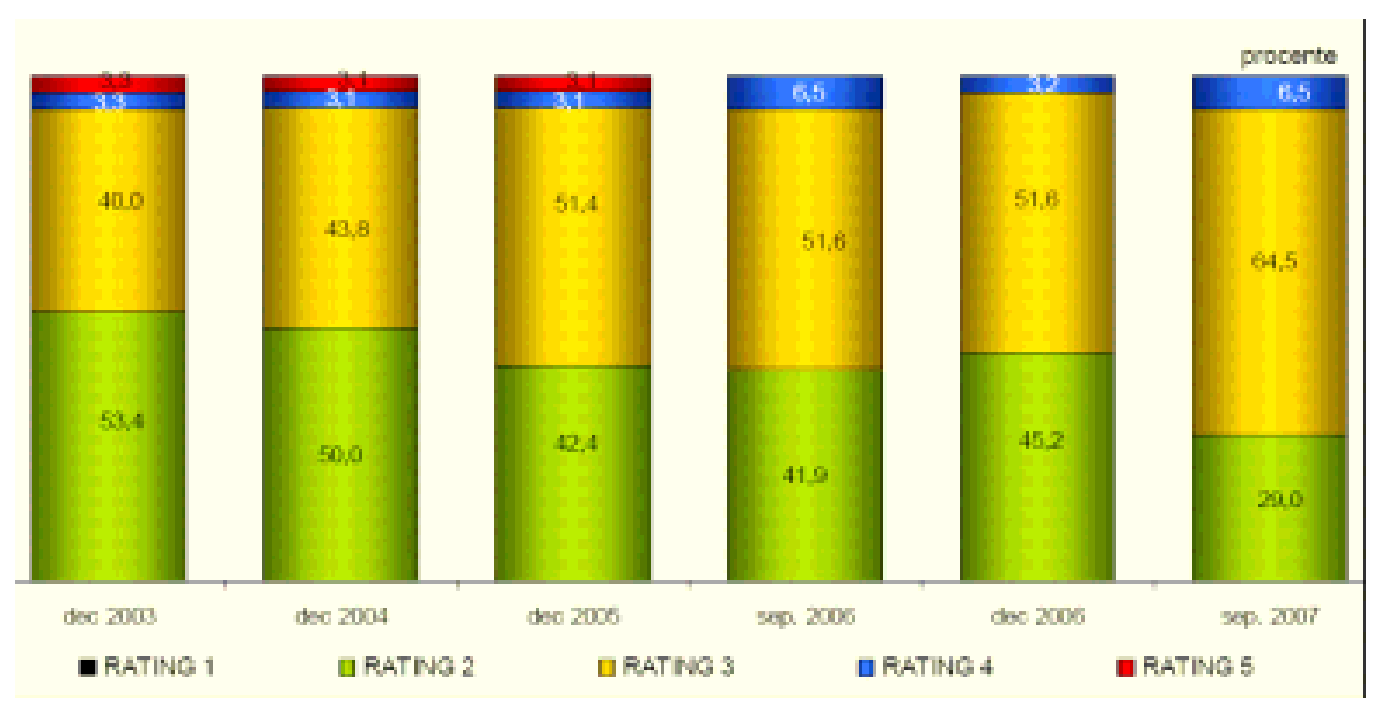

\section{Fig. no. 2. - The weight of banks classified in the five composite ratings in the banking asset volume}

Source: Georgescu Florin (2007) - Bilanțul evoluției sistemului bancar la un an de la aderarea la Uniunea Europeană, Bucharest, 2007

At the same time, beside the rating system CAAMPL, according to a study made by BNR [National Bank of Romania, 2007] it is described the mechanism of a early identification of the deterioration events of the CAAMPL rating system with one year prediction horizon, and also the results of its estimations for December $31^{\text {st }}, 2007$.

Its main component is represented by a statistic quantification of the probability of deterioration of the CAAMPL rating, estimated and tested using exclusively micro prudential data that cover the December 1999 - December 2006 period. The specific methodology of estimation, testing and implementation combines elements encountered in the specialty practice to the exigencies stipulated by 
the Basel II agreement regarding the problematic of the internal models for the credit risk, in order to obtain some high and consistent performance in time of the process of identification of the events of deterioration of the credit institutions in the Romanian banking sector.

The high accuracy of the statistic model is assured by the performance of the noting function, in the terms of the discrimination power, of the stability and of the adequate calibration of its estimations. The value of the surface indicator of the ROC curb is high and robust, the stability tests indicating reduced fluctuations around the level of $85 \%$, which represents, moreover, the appropriate value for the entire observations sample. Plus, the verification of the ex-ante delimitation capacity of the deterioration events of those of maintenance and improvement of the CAAMPL rating shows a higher performance at the level of the testing sample (January 2003 - December 2005) than that at the level of the estimation sample (December 1999 - December 2002).

The model is very well applied especially in the case of the credit institutions with a high weight in the Romanian bank system, the weighted average of the general accuracy rate being over 90 percent as opposed to 80 percent in the case of the arithmetic mean in the conditions of the calibration of the alarm limit so that the percent of the false alarms be equal to the one of the unidentified deteriorations. The performance percents are notable in the case of BNR, BRD and Raiffeisen Bank, namely 100 percent for the first and the third bank and 95,89 percent for the second one. On the other hand, in the case of three of the banks with foreign capital and of a bank with autochthonous private capital the scoring function has an unsatisfying performance. This result is determined by the great number of consigned false alarms, considering the fact that the events of deterioration of the rating are integrally signalled by the model. For these reasons, the ex-ante identification of the events of deterioration of the rating is made exclusively upon an alarm limit, the success probability of the signal furnished by the model being evaluated inclusively upon a noting scale but also through qualitative analysis.

The noting scale includes six risk classes, which assure a good segmenting of the probability of deterioration in terms of the value of the obtained score. The criteria used for its construction were the homogeneity of the events from the same class and the significant delimitation of the empirical probability of deterioration of the CAAMPL rating between the different risk categories. The empirical resulted probabilities are robust estimations in the terms of the risk of deterioration of the CAAMPL rating and allow the gradation of the alarms generated through the application of the alarm limit, especially for the values of the theoretical probability of deterioration adjacent to the level of the alarm limit. Three categories of these have low deterioration risk, one has average deterioration risk and two have high deterioration risk.

Taking into consideration the previously exposed aspects, the author of the study [Bogdan Moinescu, 2007] considers that beside the CAAMPL rating system, the use of the model of prevision of the deterioration of the rating presented in this study can contribute to the increase of the accuracy of the process of identification of the banks with financial difficulties. Thus, the central bank could administrate more efficiently the limited resources it has in order to avoid some eventual individual disequilibrium at the system level.

The results of the application of the system of provision of the events of deterioration of the CAAMPL rating for December $31^{\text {st }} 2007$ indicates 18 credit institutions with low deterioration risk, 5 with average deterioration risk and 8 with high deterioration risk. The interpretation of the signals supplied by the model based upon some qualitative information and the historic performance registered on each bank by itself leads to the following conclusions:

- the credit institutions with important weight in the Romanian banking sector will register a performance at least as good as in 2007 comparatively to 2006;

- there are no banks with composed 3 rating at the end of 2006 for which the model will signal a deterioration of the performance at the end of 2007;

- the deterioration signal of the rating in the case of five banks represents more likely a false alarm, even though the empirical downgrade probability afferent to these entities is above average;

- it is very likely that for three credit institutions summing 2 percent of the aggregated asset 
of the Romanian banking system the CAAMPL system deteriorate from 2 in December $2^{\text {nd }} 2006$ to 3 in December 2007.

At the same time we must mention that the future inclusion in the quantification model of the probability of deterioration of the CAAMPL rating of some macroeconomic variables, as the exchange rate and the interest rate or the integration of the collected information through the activity of bank inspection in the process of interpretation of the signals supplied by the statistic model can lead to the refinement of the system of prevision of the events of deterioration of the rating presented in this study. Also, as the great rating agencies will note more of the credit institutions from the Romanian bank system in report to the nine ones from the present, the utilisation of the issued ratings, but mostly of their component regarding the appreciation of the perspective will enlarge the sphere of information available for the completion of the signals supplied by the system of prevision of the events of deterioration of the CAAMPL rating. Plus, the annual reanalysis of the performance of the statistic model - expression of the application of requirement stipulated by paragraph 443 of the Basel II Agreement represents another component which will contribute to the maintenance of its accuracy at a high level in the future.

\section{Modern approaches of the global risk}

The supervising authorities, and also the theoreticians pay nowadays a special attention to the macroprudential analysis in order to evaluate the vulnerability of the bank systems to shocks. The novelty of this recent approach, consecrated at the end of the 90 's, of the last century consists in the fact that the systemic risk is analysed from the perspective of its interaction to the real economy, the focus of the supervising activity being on the contamination risk and the mutual exposure of the banks to macroeconomic shocks. We assist thus, to the minimisation of the factors specific to each bank that can have an adverse evolution and can amplify the exposure to risk.

Practically, this approach uses aggregated macro prudential quantitative indicators at the level of the bank sector (liquidity, adequate capital, the quality of the assets) and macroeconomic indicators (the GIP level and dynamics, the evolution of the inflationist process, the policy of the incomes, etc.) which concur to the establishment of the interaction between the real sector of the economy and the health of the bank system. The macro prudential analysis frame is complete when in the model are used data regarding the entire financial system and there are used techniques of the stress tests type.

We consider that the efforts of applying are considerable and the success of this type of analysis depends on the degree of integration of the financial system in every country and on the creation of some international standards so that this demarche is unitarily implemented.

The decision of the Administration Council of BNR from October 2004 through which the Direction of Financial Stability is created, having a role in the elaboration of some representative financial stability indicators for the supervision of the national financial system and to assure their international comparability, denotes the fact that the macro prudential analysis is agreeable by the monetary authority from our country too. The problem will be difficult, considering the structure of the Romanian financial system, and also the total liberalisation of the capital account, which will impose the Central Bank the enforcement of the supervision process for the assurance of the stability of the bank system.

Usually, the authorities use more warning in time systems, precisely to assure a high efficiency of the supervision. The Committee from Basel through the New Basel II Agreement set the basis of the consolidated supervision, considering the transnational character of the banks. Thus, the authority from the origin country must supervise, on a consolidated basis, the banks form the host countries, which does not exclude the compulsoriness of the banks from the host country in respecting the prudential norms specific to the banking market where they operate. The banks reciprocally supply themselves information regarding the management and the stock holding of these credit institutions, especially as far as the liquidity, the solvability the scheme of guarantying the deposits, the limitation of the great 
exposures, the accounting procedures and the internal control mechanisms are concerned.

Therefore, at the same time with the exposure of our country to the European Union, the National Bank of Romania became a member of the European System of the Central Banks, quality in which it is represented in all the its work structures. This representation supposes the participation to the regulation process at the level of the European Union which is developed on four work levels.

Among the main benefits of this process we can find the increase of the speed of adopting the decisions by delegating the components of technical regulation to the Specialty committees and the possibility of reaching in time the convergence in the plan of the supervision practices at the competent authorities from the E.U. Among the actions taken by BNR in order to reach the convergence in the plan of the practices of supervision of the banking activities we can find:

- the adapting of the reporting system of the credit institutions at the COREP requirements Common Reporting - standardised frame of prudential reporting in the EU - and FINREP Financial Reporting - standardised frame of financial reporting used by the prudential supervision authorities from the EU - through the configuration of their reporting forms and their integration in the reporting electronic system of BNR;

- the use of the recommendations elaborated by the Committee of the European Bank Supervisors (CEBS);

- the signing of ten bilateral memorandums with supervision institutions from the original country of the financial groups present on the Romanian market for the flexibility of the exchange of information necessary in the achievement of an efficient supervision;

- the participation to the information exchange with the supervisors from South-Eastern Europe by constructing a regional platform, as a consequence of the dominant role the subsidiaries of some foreign banks play in the financial intermediation of this region;

- the promotion of a mutual supervision through the participation to twinning programs, professional training seminaries, bilateral meeting between BNR as supervision authority from the host country and those from the origin country, such as Banca d'Italia, Austrian Financial Market Authority and Austrian National Bank, Hungarian Financial Supervisory Authority and Bank of Greece.

\section{Conclusions}

The recent developments focus upon sophisticated systems that use econometric techniques for the estimation of the bankruptcy probability or the deterioration of the rating. Based upon the information offered by these instruments, set off, when it is needed, inspection actions which aim for the specific identified aspects or are established the priorities in the case of the general examinations which are performed on a regulated basis. Thus, the early warning systems of the deterioration of the bank performances allow the improvement of the efficacy of the bank inspection activity and a better administration of the limited resources the prudential control authorities dispose of.

Hence, we consider that there are some challenges in the implementation of a supervision process based upon the mechanisms of evaluation of the risk management:

- The thoroughness of the qualitative aspects of the supervision process, through:

- A greater involvement of the management of the credit institutions in the process of risks administration;

- The evaluation of the credit institutions is focused upon the establishment of the risk profile of the institution;;

- The supervision consolidated upon a tight cooperation, both between the credit institutions members of the groups, and also the corresponding supervision authorities from other countries;

- The implementation of the primary and secondary legislation approved by the end of 2006 in order to apply the stipulations of the Basel II Agreement starting, the latest, by 2008; 
- The main changes in the new approach regarding the prudential supervision are:

- The diminishing of the conformity and the achievement of a prudential supervision based upon the evaluation of the risks of the credit institutions;

- The focusing more on the assurance of respecting the principles of corporatist governance

- The evaluation of the stability, the accuracy and the efficiency of the process of management of the risks of the credit institutions, especially regarding:

- $\quad$ The quality of the strategy of modernisation of the risks management;

- The efficient existence and the of the specialised and managerial support committees;

- $\quad$ The efficient functioning of an adequate internal control system;

- $\quad$ A transparent and efficient system of managerial reporting.

As a conclusion, the Basel II Agreement is the most important referential frame in the micro prudential nowadays. In the frame of the new approach, the supervision activity is oriented more and more towards the analysis of the risk profile of the credit institution, of the means and instruments existing at the hand of its leaders for the efficient administration of the specific risks. The rating and early warning systems, the stress tests and the ones of interbank contamination represent sophisticated techniques that allow the successful achievement of the previously mentioned objectives. These instruments use relevant information on the characteristics of a credit institution and its counter parties, based upon which a synthetic measure of their performances and/or vulnerability is supplied.

\section{References:}

1. Georgescu Florin (2007) - Bilanțul evoluției sistemului bancar la un an de la aderarea la Uniunea Europeană, Bucharest;

2. Georgescu Florin (2007) - Provocări pentru supravegherea sectorului financiar-bancar, Bucharest;

3. Moinescu Bogdan (2007) - Sistem de previziune a evenimentelor de deteriorare a ratingului CAAMPL, Studies Notebooks no. 23, National Bank of Romania;

4. Oprițescu Marin - coordinator (2006) - Managementul riscurilor şi performanțelor bancare, Universitaria Publishing House, Craiova;

5. xxx - (2004) "International Convergence of Capital Measurement and Capital Standards", Basel Committee on Banking Supervision.

6. xxx - (2007) "Raport asupra stabilității financiare”, National Bank of Romania;

7. $\mathrm{xxx}$ - (2008) "Buletin lunar nr. 1/2008", National Bank of Romania. 